\title{
Kalp Yetmezliği Hastalarının Öz Bakım Davranışları ve Bakım Gereksinimlerini Karşılamada Bağımsızlık Durumlarının İncelenmesi
}

\section{Investigation of Independence Status of Self-Behavior and Caring Needs of Heart Failure Patients}

\author{
'̈zlem DOĞU KÖKÇÜ, ${ }^{2}$ Öznur TIRYAKİ
}

${ }^{1}$ Sağlık Bilimleri Fakültesi, Sakarya Üniversitesi, Sakarya, Türkiye ${ }^{2}$ Sakarya Üniversitesi Eğitim ve Araştırma Hastanesi, Sakarya, Türkiye

Özlem Doğu Kökcü: https://orcid.org/0000-0003-1257-2551

Öznur Tiryaki: https://orcid.org/ 0000-0001-8788-3077

\section{ÖZ}

Amaç: $\mathrm{Bu}$ araştırma, kalp yetersizliği (KY) olan hastaların, öz bakım davranışları ve bakım bağımlılığı durumlarını belirlemek amaciyla planland.

Materyal ve Metot: Tanımlayıcı ve kesitsel nitelikteki araştırmaya 250 hasta dahil edildi. Veriler, Bakım Bağımlılığı Ölçeği, Avrupa Kalp Yetersizliği Öz Bakım Davranış1 Ölçeği ve Hasta Bilgi Formu ile topland.

Bulgular: Hastaların, yaş ortalaması 65,58 $\pm 11,71$ olup, öz bakım davranışları ortalama puanı $33,14 \pm 9,41$ ve bağımllık düzeyi $54,83 \pm 19,59$ ile orta düzeyde bağımsız olarak bulundu. Bireylerin öz bakım davranışların arasında en iyi solunum problemlerini yönettikleri $(2,55 \pm 1,48)$ en kötü ise dinlenme $(3,11 \pm 1,76)$ olduğu görüldü. Benzer şekilde insan gereksinimlerine yönelik hazırlanan bakım bağımsızlığ $(3,36 \pm 1,57)$ gösterdiği, en kötü ise tehlikelerden korunma $(3,05 \pm 1,44)$ konusunda bağımsızlık gösterdiği görüldü. Hastaların, Avrupa kalp yetersizliği öz bakım davranışları ölçeği toplam puanı ile trigliserit değeri arasından anlamlı bir farklılık ve pozitif yönde ilişki olduğu bulundu $(p<0,05)$. Benzer şekilde yalnız yaşama durumu ile bakım bağımlılığı ve öz bakım davranışı puan ortalaması arasında, New York Kalp Derneği Kalp Yetersizliği derecesi ile bakım bağımlılığı puan ortalaması arasında istatistiksel olarak anlamlı bir farkl11ık olduğu $(\mathrm{p}<0,05)$ elde edildi.

Sonuç: Hasta bireylerin öz bakım davranışlarının uygun, bakım bağımlılıklarının orta düzeyde olduğu, klinik durum kötüleştikçe ve yalnız yaşama durumuna göre öz bakımın ve bağımlılığın etkilendiği görüldü.

Anahtar Kelimeler: Kalp yetersizliği, öz bakım davranışları, bakım bağımlılığı, bağımsızlık

\section{ABSTRACT}

Objective: This study was planned to determine the independence status of patients with heart failure (HF) in line with self-care behaviors and care dependence.

Materials and Methods: The study was planned descriptively and cross-sectionally, included 250 patients Data were collected with Care Addiction Scale, European Heart Failure Self-Care Behavior Scale and Patient Information Form.

Results: The mean age of the patients was $65.58 \pm 11.71$, and the mean score of self-care behaviors was $33.14 \pm$ 9.41 and the level of dependence was $54.83 \pm 19.59$ and was independently independent. It was observed that individuals managed the best respiratory problems in their self-care $(2.55 \pm 1.48)$, the worst rest $(3.11 \pm 1.76)$. Similarly, it was found that the most independent of the care items prepared for human needs were in the nutritional activity (3.36 \pm 1.57$)$, and the worst was independence from the hazards $(3.05 \pm 1.44)$. There was a significant and positive correlation between the patients' total score of European heart failure self-care behaviors scale and triglyceride value $(\mathrm{p}<0.05)$. Similarly, it was found that there was a statistically significant difference between the living status alone and the mean of care dependence and self-care behavior, and between the New York Heart Association Heart Failure grade and the mean care dependence score $(\mathrm{p}<0.05)$.

Conclusion: Self-care behaviors of patients were found to be appropriate, care dependence was moderate, self-care and dependence were affected as the clinical condition deteriorated and living alone.

Keywords: Heart failure, self-care behaviors, care dependence, independence
Sorumlu Yazar / Corresponding Author:

Özlem Doğu Kökcü

Sağlık Bilimleri Fakültesi, Sakarya Üniversitesi, Sakarya, Türkiye Tel: $0264.2555454 / 1187$

Fax : 02642956602

GSM: 05056792063

E-mail: ozlemdogu@sakarya.edu.tr
Yayın Bilgisi / Article Info:

Gönderi Tarihi/ Received: 24/06/2019

Kabul Tarihi/ Accepted: 30/04/2020

Online Yayın Tarihi/ Published: 30/06/2020

Atıf / Cited: Doğu Kökcü Ö, Tiryaki Ö. Kalp Yetmezliği Hastalarının Öz Bakım Davranışları ve Bakım Gereksinimlerini Karşılamada Bağımsızlık Durumlarının İncelenmesi . Online Türk Sağllk Bilimleri Dergisi 2020;5(2):364-374. doi: 10.26453/otjhs.581600 


\section{Giriș}

Kalp yetersizliği (KY), kalbin dinlenme esnasında dahi dokulara yeterli miktarda kanı pompalayamadığ1, kardiyak outputun azalması ve intrakardiyak basıncın artması ile karakterize olan dispne, ödem, öksürük, yorgunluk semptomlarının gözlendiği, yapisal ve fonksiyonel klinik sendromdur. ${ }^{1,2} \mathrm{KY}$ tedavisinde tam iyileşmenin olmaması, tedavisinin ömür boyu devam etmesi ve kompleks bir sendrom olmas1 nedeniyle hastaneye tekrar yatışlara ve sağlık harcamaları açısından ek maliyetlere neden olmaktadır., ${ }^{3,4}$ KY'nde semptomları ve tedaviyi yönetmek için bireyin yaşam şeklinde değişikliği zorunlu kılmakta olup, yeterli uyum ve davranış sağlanmadığında bireylerin yaşam kalitesi olumsuz etkilenmektedir. Yapılan çalışmalarda bireylerin verilen diyet ve ilaç tedavisi önerilerine uyum sağlaması halinde, hastaneye tekrar yatışların azaldığı belirtilmektedir. ${ }^{5-7}$

KY hastalarında yaşam kalitesini olumsuz etkileyen birçok faktör bulunmaktadır. Bunlar; KY'nin evresi, komorbit hastalıkların bulunması (diyabet, akciğer rahatsılılkları vb.), günlük yaşam aktivitelerinin sınırlanmasına neden olan semptomların şiddeti ve sıklığı, bireyin tedavisini uyum sağlamaması ve yönetmesinde uyumsuzluk, ileri yaş, bakımını gerçekleştirmede yetersizlik, sosyal ve psikolojik desteğin azlığı, olumsuz sağlık davranışları (sigara vb.) olarak siralanmaktadır. ${ }^{7,8}$

İlk defa Dorothea Orem tarafindan vurgulanan "öz bakım kavramı" "bireyin yaşamını, sağlık ve iyiliğini korumak için kendine düşeni yapmasıdır" şeklinde ifade edilmekte olup, bireyin kendisi ile ilgili aktiviteleri gerçekleştirme yeteneği ise; öz-bakım gücü olarak tanımlanmaktadır., ${ }^{9,10} \mathrm{KY}$ 'de öz bakım, tedavinin başarısında önemli rol almaktadır. Bireyin düzenli olarak ilaçlarını kullanması, hekim kontrolü, beslenme alışkanlığında değişiklik, semptomların izlenmesi ve yönetimi, öz bakım aktivitelerini gerçekleştirmesi, kendi sağlığının sorumluluğunu alabilmesi ve başkalarına bağımlı olmaması beklenmektedir. Ancak eğitim düzeyinin düşük olması, ileri yaş, hastalığı kabullenmeme, semptomları tanımada zorluklar yaşanması, uzun süren tedavi ve bakım süreci, bu süreçte yeterli sağlık ve sosyal desteği alamaması gibi nedenlerle öz bakımları olumsuz etkilenmekte ve bakımda bağımlılığa neden olmaktadır. ${ }^{4-6,9} \mathrm{KY}$ hastalarının bağımsızlık durumlarının ve bakım gereksinimlerinin belirlenmesinde hemşirelere önemli roller düşmektedir. Çağdaş hemşirelik rolleri arasında yer alan bakım verici rolü ile bireye özgü hemşirelik bakımını planlamada hemşirelerin
KY hastaları bütüncül değerlendirmesi gerekmektedir. ${ }^{11-13}$ Hastanede yatan KY hastalarının bakım bağımlılığının belirlenerek, taburculuk öncesi hastaya verilecek olan hemşirelik bakımına rehber olacağı düşünülmektedir. Bu doğrultuda araştırma, kalp yetmezliği olan bireylerin öz bakım davranışları ve bakım bağımlılığını değerlendirmek için planlanmıştir.

\section{MATERYAL VE METOT}

Tanımlayıcı ve kesitsel nitelikte planlanan çalışma bir eğitim ve araştırma hastanesinin kardiyoloji kliniğinde Haziran 2018-Şubat 2019 tarihleri arasında gerçekleştirildi. Çalışma için Sakarya Üniversitesi Tıp Fakültesi, Girişimsel Olmayan Etik Kurulundan onay alındı (Tarih; 02/04/2018, karar no; 71).

Evren ve Örneklem: Evrenini belirtilen tarihlerde klinikte KY tanısı ile yatan bireyler oluştururken, örneklemini çalışma hakkında bilgilendirildikten sonra katılmayı kabul eden, KY tanısı konulmuş, bilinci açık, 18 yaş üzeri, araştırmaya katılmaya gönüllü ve istekli olan 250 hasta oluşturdu.

Veri Toplama Araçları: Çalışma verilerinin toplanmasında hastaların sosyodemografik özelliklerini içeren "Hasta Bilgi Formu", Bakım Bağımlığı Ölçeği” ve "Avrupa Kalp Yetersizliği Öz Bakım Davranışı Ölçeği” kullanılmış olup, araştırmacılar tarafından 10-15 dakikalık görüşme süresinde toplanmıştır. Hasta Bilgi Formu: Araştırmacılar tarafından literatür doğrultusunda hazırlanan soru formu; katılımc1ların yaş, cinsiyet, sağlık ve hastalık öyküleri, New York Kalp Cemiyeti'nin (NYHA) konjestif kalp yetersizliği sinıflaması, kan tahlilleri vb bilgileri içermektedir.

Bakım Bă̆ımlılığı Ölçeği (BBÖ): Dijkstra ${ }^{13}$ tarafından geliştirilen, Türkiye'de geçerlik ve güvenirlik çalışmasını Hakverdioğlu Yönt ve ark. ${ }^{14}$ tarafindan 2010 yılında yapılan ölçek, Virginia Henderson'ın insan gereksinimlerine göre temellendirilmiş ve hastaların bakım bağımlılık durumlarını değerlendirmek amaciyla geliştirilmiştir. Ölçek beş'li likert tipi ve 17 maddeden oluşmaktadır.

Avrupa Kalp Yetersizliği Öz, Bakım Davranışı Ölçeğ $\mathbf{i}$ (АКYÖB̈̈): Jaarasma, Stromberg, Martensson ve Dracup ${ }^{15}$ tarafindan geliştirilmiş olup, Türkçe uyarlaması Baydemir ve ark. $^{3}$ tarafından 2013 y1lında yapılmıştır. Ölçek KY hastalarının öz bakımını değerlendirmek amacıyla yaşam aktivitelerine yönelik 12 sorudan oluşmaktadır. АKYÖBÖ beş'li likert tipi olan ölçekten en fazla 60 , en az 12 puan alınmaktadir. 
İstatistiksel Analiz: Veriler analiz edilirken SPSS for Windows Release 21.0 (Statistical Package for Social Sciences Inc. Chicago, IL, ABD) istatistiksel paket programı kullanıldı. Değişkenlerin frekans dağılımları sayı ve yüzde olarak incelendi. Ölçeklerin güvenilirliğinde cronbach alpha değerine bakılırken, diğer veriler pearson kolerasyon, mann whtney $\mathrm{u}$ ve kruskal wallis testi ile değerlendirildi. Yapılan istatistiksel analizlerde anlamlılık düzeyi $\mathrm{p}<0,05$ olarak alındı.

\section{BULGULAR}

Çalışmaya dahil edilen kalp yetmezliği tedavisi altında ki hastaların yaş ortalaması $65,58 \pm 11,71, \%$ 54,4'ü kadın, \%85,2'si evli, \%87,2'si okuryazarlilkokul düzeyinde eğitime sahip, $\% 92,8$ 'si çalışmiyor ve \%75,6's1 ekonomik durumunu iyi olarak ifade etti. Bireylerin çoğunluğu $(\% 51,6)$ beslenme alı̧kanlığının düzenli olduğu belirtirken, yine çoğunluğunun sigara kullanmadığı $(\% 74,8)$ gözlemlendi (Tablo 1).

Çalışmada Avrupa Kalp Yetersizliği Öz Bakım Davranışı Ölçeğinin Cronbach alfa değeri 0,71 olduğu görüldü (Table 2). Kalp yetmezliği tedavisi olan bireylerin öz bakım davranışları incelendiğinde; dinlenme $(3,11 \pm 1,76)$, az tuzlu beslenmeye dikkat etme $(2,91 \pm 1,49)$, ilaçları hekimin önerdiği şekilde kullanma $(2,82 \pm 1,72)$ ve kilo alma durumunda doktor ya da hemşireye haber verme $(2,94 \pm 1,52)$ davranışlarında yetersiz oldukları; kilo takibi yapma $(2,56 \pm 1,51)$, solunumu takip etme $(2,56 \pm 1,54)$, hareketi sağllk durumuna göre yönlendirme $(2,55 \pm 1,48)$ ve egzersiz $(2,78 \pm 1,70)$ davranışlarında kısmen yeterli oldukları görüldü. Elde edilen sonuçlar doğrultusunda Öz bakım davranışları ortalama puanı 33,14 $\pm 9,41$ olarak bulunmuştur.

Çalışmada Bakım Bağımlılığı Ölçeğinin Conbach alfa değeri 0,76 olarak bulundu (Table 2). Bireylerin bakım bağımlılığı durumları incelendiğinde ise; uykuya gitme ve sürdürebilmede $3,11 \pm 1,40$, vücut temizliğini yapabilmede $3,07 \pm 1,50$, başkalarından ve çevreden gelebilecek tehlikelere karşı kendini koruyabilmede $3,05 \pm 1,44$, ibadet gereksinimlerini karş1layabilmede $3,14 \pm 1,53$, günlük aktivitelerini sıralayabilmede $3,10 \pm 1,43$ ve sosyal aktiviteleri karşılamada $3,12 \pm 1,40$ ve bağımlılık düzeyi $54,83 \pm 19,59$ elde edildi (Tablo 3 ).

Hasta bireylerin potasyum, glukoz, kolesterol, sodyum, kalsiyum, BUN, ürik asit, kreatin, myoglobin, hemoglobin ve ejeksiyon fraksiyonu ortanca değer- leri bakımından ölçek puan ortalamaları arasında istatistiksel olarak anlamlı bir farklılık olmadığ $(p>0,05)$, trigliserit, ortanca değeri ile АKYÖBÖ arasında istatistiksel olarak anlamlı bir farklılık ve pozitif yönde ilişki olduğu saptandı $(\mathrm{p}<0,05)(\underline{\text { Tablo }}$ 4).

Tablo 5 incelendiğinde, hasta bireylerin bağımsızlık durumunu etkileyebilecek bazı değişkenler ile öz bakım davranışı ve bakım bağımlılı̆̆ puan ortalamaları karşılaştırılmıştır. Karşılaştırmaya göre bireyin yalnız ya da ailesi ile yaşaması, New York Kalp Derneği Kalp Yetersizliği derecesi ile bakım bağımlılığ anlamlı bir farklılık olduğu $(\mathrm{p}<0,05)$, benzer şekilde yalnız yaşama durumu ile Avrupa Kalp Yetersizliği Öz Bakım Davranışı ortalaması ile arasında istatistiksel olarak anlamlı bir farklılık olduğu $(\mathrm{p}<0,05)$ görüldü.

\section{TARTIŞMA VE SONUÇ}

Kalp yetmezliği tedavisinde son ylllarda önemli gelişmeler yaşanmasına rağmen, tedavisinin uzun sürmesi, görülme sıklığının her geçen gün artması, yüksek morbidite ve mortaliteye sahip olması nedeniyle bir halk sağlığı problemi olarak görülmektedir., ${ }^{3,4}$

Bireyin kendi tedavi, bakım ve semptomlarını yönetmesi için yeterli öz bakım gücüne gereksinim vardır. Bireyin öz bakımında ki artış bağımlılık durumunda azalmanın bir göstergesi iken yaşam kalitesinin de yükselmesi anlamındadır. АKYÖBÖ ölçekte 12-36 puan öz-bakım davranışın uygun ve 37-60 arası puan öz-bakım davranışın yetersiz olduğunu göstermektedir. ${ }^{3,15}$ Çalışmamızda bireylerin öz bakım davranışlarından bazı günlük aktivitelerde yeterlilik gösterdiği, bazılarında ise yetersizlik gösterdiği ve öz bakım davranışları puanının 33,14 $\pm 9,41$ olarak uygun düzeyde olduğu bulunmuştur (Tablo 3 ).

Kalp yetmezliği hastalarında öz bakım gücünün düşük olması tedavi ve bakımda hayati sorunlara neden olacağından önemli bir sorundu. Baydemir ve ark. ${ }^{3}$ çalışmalarında benzer sonuçlar elde ederken, Pour ve ark. ${ }^{4}$ ile Sedlar ve ark. ${ }^{16}$ ise KY hastalarını öz bakımının düşük olduğunu saptamıştır. Sedlar ve ark. ${ }^{17}$ derleme niteliğinde ki çalışmalarında otuz çalışmayı değerlendirmiş ve genel olarak öz bakım davranışların KY hastalarında düşük olduğu ve etkileyen faktörlerin yaş, psikolojik faktörler ve NYHA derecesi ile ilişkili olduğunu belirtmiştir. Çalışmalarda farklı sonuçlar elde edilmesinin toplumsal yapı ve kültürel farklılıklardan kaynaklı olduğu düşünülmekte olup, örneklemimizi oluşturan bireylerin öz- 
bakım davranışın uygun olması olumlu bir sonuçtur. Çalışmada BBÖ ölçeği kullanılarak bağımlılık durumlarının belirlenmesi amaçlandı. BBÖ ölçeğinden alınan puanın yüksek olması, hastanın bakım gereksinimlerini karşılarken bağımsız olduğunu, düşük olması ise başkalarına bağımlı olduğunu göstermektedir. Katılımcıların bakım bağımlılığı ölçek puanının orta düzeyde elde edilerek, orta düzeyde bağımsız olduğu sonucuna varıldı. Maddeler değerlendirildiğinde ise; uykuya gitme ve sürdürebilmede, vücut temizliğini yapabilmede, başkalarından ve çevreden gelebilecek tehlikelere karşı kendini koruyabilmede, ibadet gereksinimlerini karşılayabilmede, günlük aktivitelerini sıralayabilmede ve sosyal aktiviteleri karşılamada kısmen başkalarına bağımlı olduğu görüldü (Tablo 3 ).

KY'nin kronik bir hastalık olması, ileri yaşta görünme oranın fazla olması, yaşanan semptomların fiziksel yetersizliğe neden olması ve günlük yaşam aktivitelerinde bağımlılı̆̆ın artmasına yol açmaktadır. $\mathrm{Bu}$ durum KY için beklenen bir sonuç olup, literatür ile de desteklenmektedir. ${ }^{11,18}$ Çalışmamıza benzer şekilde KY hastalarında bakım bağımlılığını değerlendiren sınırlı sayıda çalışma bulunmuştur. Ancak kronik hastalıklar ile yapılan çalışmalarda da benzer sonuçlar elde edilmiştir. Helvacı, ${ }^{19}$ eğitim ve danışmanlık uyguladığı KOAH hastalarında uygulama öncesinde yüksek olan bakım bağımlılığının düştügünü, Kaya, ${ }^{20}$ diyabetik ayak hastalarında ek hastalıklar arttıkça puan ortalamasının etkilendiğini belirtmiştir. Janssen ve ark.' nın ${ }^{8} \mathrm{KY}$ veya KOAH gibi kronik hastalıklarda bakım bağımlılığı ve sağlık durumunun etkilenmesini değerlendirmiş ve ileri yaşın bakım bağımlılığına olumsuz etki ettiğini vurgulamıştır.

Sedlar ve ark. ${ }^{17} 104$ kalp yetmezliği hastası ile yaptığ1 çalışmada yüksek kolesterol düzeyinin öz bakım davranışının yetersizliğinin bir göstergesi olduğu sonucuna varmış, benzer şekilde $\mathrm{Wu}$ ve ark. ${ }^{21}$ iki değişken arasında ilişki olduğunu belirtmiştir. Çalışmamızda bireylerin trigliserit değeri ile öz bakım davranışları puan ortalaması arasında pozitif yönde ilişki olduğunu, trigliserit değeri arttıkça kalp yetmezliği öz bakım davranışı puanının da arttığı ve yetersiz öz bakım davranışı olduğunu düşündürmüştür (Tablo 4).

Araştırmamıza göre ailesi ile yaşayan hastaların öz bakım davranışları ve bakım bağımlılı̆̆ı durumu yalnız yaşayan hastalara göre daha iyi olduğu saptanmıştır. Kronik hastalıkların yönetiminde bireyin fiziksel-sosyal çevresi gibi destek sistemlerinin olması, hastalığa uyum sürecinde ve kronik hastalığın yarattığı sonuçlarda önemli etkileri olduğu bildirilmektedir. ${ }^{22,23}$ KY olan 117 hasta ve ailesi ile yapilan randomize bir çalışmada da, zayıf aile desteği olan bireylerin diyet ve ilaç kullanımı uyumu, motivasyon ve güven duygusunun düşük seviyede olduğu belirlenmiştir. ${ }^{24}$ Başka bir çalışmada da KY hastalarının hemşirelik bakımında aile işbirliği ve desteği doğrultusunda yaşam tarzı değişikliğinin, yaşam kalitesinin iyileştiği ve dolayısıyla hastaneye başvuruların azaldığı belirtilmiştir. ${ }^{25}$ Ataerkil kültürel özelliğe sahip toplumumuzda yalnız yaşayan birey sayısının az olması ve belirtilen çalışma sonuçları çalışmamızın bu bulgusunu destekler niteliktedir.

Çalışmamızda bireylerin NYHA sınıf IV hastaların bakım bağımlılı̆̆ı, sınıf I hastalara göre daha kötü olduğu saptanmıştır (Tablo 5). Baydemir ve ark. ${ }^{3}$ da çalışmalarına dahil ettikleri hastaların çoğunluğunun sınıf III ve IV olduğunu ve öz-bakım güçlerinin zayıf olduğunu belirtmiştir. Öz bakım gücünün zayıf olması dolayısıyla gereksinimlerini karşılamada bağımlılığın artmasına neden olacağı düşünülmektedir. Yapılan iki çalışmada kalp yetersizliği olan hastaların en çok bağımlı olduğu alanların; mobilite, hijyen, giyinme/soyunma, kontinans, tehlikelerden kaçınma ve günlük aktiviteler olduğu belirtilmiştir. ${ }^{18,25}$ NYHA sinıflandırması KY'nin değerlendirmenin yollarından biri olup, hastaların günlük aktivitelerini yerine getirirken ne kadar zorlandığını ve hastalığın günlük hayata etkisini belirlemek amacıyla geliştirilmiştir. Buna bağlı olarak KY hastalarında sınıflandırma derecesi arttıkça her alanda kısıtlama yaşamaktadırlar. Bu sebeple kullandığımız NYHA sınıflandırması ile bakım bağımlılığı ölçeğinin etkilenmesi beklendik bir bulgudur.

$\mathrm{Bu}$ sonuçlar doğrultusunda; KY hastalarının hastalıklarını yönetmede, öz bakımlarını sürdürmede ve dolayısıyla tekrar yatışların, mortalite ve morbilitenin azalması ve yaşam kalitesinin yükselmesinde hastalara kazandırılması gereken beceriler ve uygun öz bakım davranışları vardır. Bu süreçte bakım ve eğitim rolü kapsamında hemşirelere önemli roller düşmektedir. KY hastalarının öz bakım aktivitelerinin ve bağımlılık durumlarının sürekli takip edilmesi ve etki edebilecek özellikler konusunda farkında olmaları ve taburculuk öncesi destek olmaları önerilmektedir. Sağlanması gereken desteğin tek seferde verilecek eğitim olarak değil, sürekliliğinin sağlanması ve hasta bireyin her ihtiyaç duyduğunda ulaşabilmesi önemlidir. Son y1llarda her alanda artan 
uzaktan- online eğitim ve danışmanlık hizmetleri gibi uygulamalar bu konuda destek olabilmektedir.

Etik Komite Onayı: . Çalışma için Sakarya Üniversitesi Tıp Fakültesi, Girişimsel Olmayan Etik Kurulundan onay alındı (Tarih; 02/04/2018, karar no; 71). Çıkar çatışması: Yazarlar arasında çıkar çatışması yoktur..

Yazar katkılart: Fikir: ÖDK, ÖT; Denetleme ÖDK; Malzemeler: ÖDK, ÖT; Veri toplanması ve/veya işlenmesi: ÖDK, ÖT; Analiz ve/veya yorum: ÖDK; Makale yazımı: ÖDK, ÖT.

Hakem değerlendirmesi: Dış bağımsız.

\section{KAYNAKLAR}

1. Sarı İ, Çavuşoğlu Y, Temizhan A, Birhan Yı1maz M, Eren M. 2016 Avrupa ve Amerika Kalp Yetersizliği Kılavuz Güncellemeleri: Yenilikler, benzerlikler, farklılıklar ve netlik kazanmamış konular. Turk Kardiyol Dern Ars. 2016;44 (8):625-636 doi: 10.5543/tkda.2016.00532

2. Crawford Michael H. Current diagnosis and treatment cardiology. 2th. ed. McGraw Hill Medical; 2009.

3. Baydemir C, Özdamar K, Ünalır A. Validity of the Turkish version of the European heart failure self-care behavior scale. Anadolu Kardiyol Derg. 2013;13:573-9.

4. Pour AH, Gökçe S, Kunter D, Yöntem H. Kalp yetersizliği olan hastalarda öz bakım davranışlarının değerlendirilmesi. F.N. Hem. Derg. 2016;24(2):66-71.

5. Hatchett R, Thompson D. Cardiac nursing. Churchill Livingstone, Philadelphia, 2002: 190214.

6. Oğuz S. Kronik kalp yetersizliği olan bireylerin hastalık yönetimine ilişkin inanç ve uyumları. Kalp Yetersizliği Elektronik Haber Bülteni. 2009;1(11):408-411.

7. Özdemir VA. Kronik kalp yetmezliği olan hastalarda yaşam kalitesinin değerlendirilmesi. Marmara Üniversitesi Sağlık Bilimleri Enstitüsü İç Hastalıkları Hemşireliği Anabilim Dalı, (Yüksek Lisans Tez). İstanbul, Türkiye. 2009.

8. Janssen DJ, Franssen FM, Wouters EF, Schols JM, Spruit MA. Impaired health status and care dependency in patients with advanced COPD or chronic heart failure. Quality of Life Research. 2011;20(10):1679-88.

9. Özer S, Sezgin D. Kalp yetersizliğinde öz bakım. Kalp Yetersizliği Elektronik Haber Bülteni.
2015;7(4):1-4.

10. Velioğlu P. Hemşirelikte kavram ve kuramlar. İstanbul, Akademi Yayınevi; 2012, 183-224.

11. Akın Korhan E, Hakverdioğlu Yönt G, Tokem Y, Karadağ Ö, Sarığlu E, Yıldız K. Dahiliye ve cerrahi kliniklerde yatan hastaların bakım bağımlılığı düzeylerinin belirlenmesi. Anadolu Hemşirelik ve Sağlık Bilimleri Dergisi. 2013;16 (4):199-204.

12. Aşti, T.(Ed) ve Karadağ, A.(Ed). Hemşirelik esasları. 1.cilt. İstanbul, Akademi yayıncılı; 2018.220-228.

13. Dijkstra A, Buist G, Brown L, Haven B, Romoren T, Zanotti R, ve ark. An international psychometric testing of the Nursing-Care Dependency (NCD) scale. Journal of Advanced Nursing. 2000;4:944-952.

14. Hakverdioğlu Yönt G, Akın Korhan E, Khorshid L, Eşer İ, Dijkstra A. Bakım bağımlılığı ölçeğinin (care dependency scale) yaşlı bireylerde geçerlik ve güvenirliğinin incelenmesi. Turkish Journal of Geriatrics. 2010;13:71 (Özel Say1).

15. Jaarsma T, Strömberg A, Mårtensson J, Dracup $\mathrm{K}$. Development and testing of the European Heart Failure Self-Care Behaviour Scale. Eur J Heart Fail. 2003;5:363-70.

16. Sedlar N, Lainscak M, Mårtensson J, Strömberg A, Jaarsma T, Farkas J. Factors related to selfcare behaviours in heart failure: A systematic review of European Heart Failure Self-Care Behaviour Scale studies. European Journal of Cardiovascular Nursing. 2017a;16(4):272-282. doi: 10.1177/1474515117691644

17. Sedlar N, Socan G, Farkas J, Mårtensson J, Strömberg A, Jaarsma T, ve ark. Measuring selfcare in patients with heart failure: A review of the psychometric properties of the European Heart Failure Self-Care Behaviour Scale (EHFScBS). Patient Education and Counseling. 2017;1304-1313. https://doi.org/10.1016/ j.pec.2017.02.005 (2017b)

18. Köberich S, Lohrmann C, Dassen T. Care dependency in patients with chronic obstructive pulmonary disease and heart failure - a secondary data analysis of german prevalence studies. Scand J Caring Sci. 2013;28(4):665674. doi: 10.1111/scs.12091

19. Helvacı A. Kronik Obstrüktif Akciğer Hastalar1na verilen eğitim ve danışmanlık programının dispne, sağlık durumu ve bakım bağımlılığı üze- 
rine etkileri. Hacettepe Üniversitesi Sağlık Bilimleri Enstitüsü İç Hastalıkları Hemşireliği Anabilim Dalı, Yüksek Lisans Tezi. Ankara, Türkiye. 2018.

20. Kaya D. Diyabetik ayak gelişen bireylerin bağımlılık durumu ve aileye olan bakım yükünün belirlenmesi. İstanbul Üniversitesi Sağlık Bilimleri Enstitüsü Cerrahi Hastalıkları Hemşireliği Anabilim Dalı, Yüksek Lisans Tezi. İstanbul, Türkiye, 2017.

21. Wu JR, Corley DJ, Lennie TA, Moser DK. Effect of a medication- taking behavior feedback theory-based intervention on outcomes in patients with heart failure. J Card Fail. 2012;18:1-9.

22. Jónsdóttir H. Nursing care in the chronic phase of COPD: a call for innovative disciplinary research. Journal of Clinical Nursing. 2008;17 (7):272-290.

23. Stamp KD, Dunbar SB, Clark PC, Reilly CM, Gary RA, Higgins M, ve ark. Family partner intervention influences self-care confidence and treatment selfregulation in patients with heart failure. European Journal of Cardiovascular Nursing. 2016;15(5):317-327. doi: $10.1177 / 1474515115572047$

24. Hasanpour-Dehkordi A, Khaledi-Farb A, Khaledi-Farc B, Salehi-Tali S. The effect of family training and support on the quality of life and cost of hospital readmissions in congestive heart failure patients in Iran. Applied Nursing Research. 2016;31,165-169. doi: https:// doi.org/10.1016/j.apnr

25. Lohrmann C, Dijkstra A, Dassen T. Care Dependency: testing the german version of the care dependency scale in nursing homes and on geriatric wards. Scand J Caring Sci. 2003;17(1): 51-56. 
Tablo 1. Bireylerin demografik ve sağlık parametreleri $(\mathrm{N}=250)$.

\begin{tabular}{|c|c|c|c|}
\hline \multicolumn{2}{|l|}{ Değiş̧kenler } & \multirow{2}{*}{$\begin{array}{c}\mathbf{n} \\
136 \\
\end{array}$} & \multirow{2}{*}{$\begin{array}{c}\% \\
54,4 \\
\end{array}$} \\
\hline & Kadın & & \\
\hline Cinsiyet & Erkek & 114 & 45,6 \\
\hline \multirow{2}{*}{ Medeni durum } & Evli & 213 & 85,2 \\
\hline & Bekar & 37 & 14,8 \\
\hline \multirow{4}{*}{ Eğitim durumu } & Okuryazar/ilkokul & 218 & 87,2 \\
\hline & Orta & 15 & 6,0 \\
\hline & Lise & 9 & 3,6 \\
\hline & Üniversite & 8 & 3,2 \\
\hline \multirow{2}{*}{ Çalışıyor musunuz? } & Evet & 18 & 7,2 \\
\hline & Hayır & 232 & 92,8 \\
\hline \multirow{2}{*}{ Ekonomik Durumunuz } & Gelirim giderlerimi karşılamıyor & 61 & 24,4 \\
\hline & Gelirim giderlerimi karşılıyor & 189 & 75,6 \\
\hline \multirow{2}{*}{ Beslenme Alışkanlığınız } & Düzenli & 129 & 51,6 \\
\hline & Düzensiz & 121 & 48,4 \\
\hline \multirow{3}{*}{ Sigara kullanma durumu } & Evet & 20 & 8,0 \\
\hline & Hayır & 187 & 74,8 \\
\hline & Bıraktım & 43 & 17,2 \\
\hline \multirow{3}{*}{ Gode } & 1 & 25 & 10,0 \\
\hline & 2 & 162 & 64,8 \\
\hline & 3 & 63 & 25,2 \\
\hline
\end{tabular}


Tablo 2. Bakım bağımlılığı ve taburculuğa hazır oluş ölçekleri Cronbach Alpha katsayısı.

\begin{tabular}{|l|c|}
\hline Ölçekler & Cronbach Alpha $(\boldsymbol{\alpha})$ \\
\hline Bakım Bağımlılığı Ölçeği & 0,76 \\
\hline Avrupa Kalp Yetersizliği Öz Bakım Davranışı Ölçeği & 0,71 \\
\hline
\end{tabular}


Tablo 3. Bireylerin öz bakım davranışları durumu.

\begin{tabular}{|c|c|}
\hline Avrupa Kalp Yetersizliği Öz Bakım Davranışı Ölçeği & $\chi^{ \pm \text {sd }}$ \\
\hline Her gün tartılırım & $2,60 \pm 1,69$ \\
\hline $\begin{array}{l}\text { Solunum sıkıntım (nefes darlığım)olursa, onu rahatlatacak şekilde davranırım (adımlarımı } \\
\text { yavaşlatmak, dinlenmek) }\end{array}$ & $2,55 \pm 1,48$ \\
\hline $\begin{array}{l}\text { Solunum sıkıntım (nefes darlığım) artarsa, doktorumu veya } \\
\text { hemşiremi ararım }\end{array}$ & $2.56 \pm 1.51$ \\
\hline Ayaklarım/bacaklarım normalden fazla şişerse doktorumu veya hemşiremi ararım & $2,56 \pm 1,54$ \\
\hline $\begin{array}{l}\text { Eğer bir hafta içinde iki kilo alırsam (ağırlaşırsam, kazanırsam), doktorumu veya hemşire- } \\
\text { mi ararım }\end{array}$ & $2,94 \pm 1,52$ \\
\hline İçtiğim sıvı miktarını kısıtlarım (günde 1,5-2 litreden fazla olmamak üzere). & $2,85 \pm 1,45$ \\
\hline Gün içinde dinlenirim & $3,11 \pm 1,76$ \\
\hline Yorgunluğumun artığını hissedersem doktorumu veya hemşiremi ararım & $2,74 \pm 1,45$ \\
\hline Az tuzlu bir diyetle (yiyeceklerle) beslenirim & $2,91 \pm 1,49$ \\
\hline İlaçlarımı önerildiği şekilde alırım & $2,82 \pm 1,72$ \\
\hline Her yıl grip aşısı olurum & $2,68 \pm 1,74$ \\
\hline Düzenli egzersiz yaparım & $2,78 \pm 1,70$ \\
\hline Avrupa Kalp Yetersizliği Öz Bakım Davranışları Ortalama Puan & $33,14 \pm 9,41$ \\
\hline \multicolumn{2}{|l|}{ Bakım Bağımlılığı Ölçeği } \\
\hline Beslenme & $3,36 \pm 1,57$ \\
\hline Kontinans & $3,26 \pm 1,48$ \\
\hline Beden Duruşu & $3,17 \pm 1,41$ \\
\hline Hareketlilik & $3,20 \pm 1,41$ \\
\hline Gündüz Gece Döngüsü & $3,11 \pm 1,40$ \\
\hline Giyinme Soyunma & $3,20 \pm 1,50$ \\
\hline Vücut Sıcaklığ1 & $3,31 \pm 1,49$ \\
\hline Vücut Temizliği & $3,07 \pm 1,50$ \\
\hline Tehlikelerden Kaçınma & $3,05 \pm 1,44$ \\
\hline İletişim & $3,35 \pm 1,57$ \\
\hline Başkaları İle İlişki Kurma & $3,38 \pm 1,53$ \\
\hline İbadet Yapma & $3,14 \pm 1,53$ \\
\hline Kurallara Uyma & $3,25 \pm 1,54$ \\
\hline Günlük Aktivite & $3,10 \pm 1,43$ \\
\hline Eğlence Aktiviteleri & $3,12 \pm 1,40$ \\
\hline Bellek Hafiza & $3,33 \pm 1,43$ \\
\hline Öğrenme Yeteneği & $3,28 \pm 1,47$ \\
\hline Bakım Bağımlılığı Ölçeği Ortalama Puan & $54,83 \pm 19,59$ \\
\hline
\end{tabular}


Tablo 4. Bireylerin BBÖ ve AKYÖBÖ ortalamaları ile kan değerleri arasındaki ilişkinin incelenmesi $(\mathrm{N}=250)$.

\begin{tabular}{|c|c|c|c|c|c|}
\hline Değiş̧kenler & Min-Max & Ortanca & & BBÖ & АKYÖBÖ \\
\hline Potasyum & $2,90-6,50$ & 4,40 & $\begin{array}{l}\mathrm{r} \\
\mathrm{p}\end{array}$ & $\begin{array}{l}0,018 \\
0,773\end{array}$ & $\begin{array}{l}0,007 \\
0,917\end{array}$ \\
\hline \multirow{2}{*}{ Glukoz } & \multirow{2}{*}{$55,00-455,00$} & \multirow{2}{*}{140,50} & $\mathrm{r}$ & 0,006 & $-0,110$ \\
\hline & & & $\mathrm{p}$ & 0,920 & 0,082 \\
\hline \multirow{2}{*}{ TC } & \multirow[t]{2}{*}{$19,00-429,00$} & \multirow[t]{2}{*}{160,50} & $\mathrm{r}$ & 0,038 & 0,079 \\
\hline & & & $\mathrm{p}$ & 0,546 & 0,216 \\
\hline \multirow{2}{*}{ Trigliserit } & \multirow[t]{2}{*}{$32,00-454,00$} & \multirow[t]{2}{*}{94,50} & $\mathrm{r}$ & 0,027 & $\mathbf{0 , 1 5 1}$ \\
\hline & & & $\mathrm{p}$ & 0,675 & 0,017 \\
\hline \multirow{2}{*}{ Sodyum } & \multirow[t]{2}{*}{$122,00-147,00$} & \multirow[t]{2}{*}{139,00} & $\mathrm{r}$ & $-0,073$ & $-0,081$ \\
\hline & & & $\mathrm{p}$ & 0,253 & 0,202 \\
\hline \multirow{2}{*}{ Kalsiyum } & \multirow[t]{2}{*}{$5,20-9,90$} & \multirow[t]{2}{*}{8,50} & $\mathrm{r}$ & 0,050 & 0,011 \\
\hline & & & $\mathrm{p}$ & 0,433 & 0,865 \\
\hline \multirow{2}{*}{ BUN } & \multirow[t]{2}{*}{$13,00-234,00$} & \multirow[t]{2}{*}{68,50} & $\mathrm{r}$ & $-0,041$ & 0,058 \\
\hline & & & $\mathrm{p}$ & 0,517 & 0,364 \\
\hline \multirow[b]{2}{*}{ ÜrikAsit } & \multirow[t]{2}{*}{$, 10-24,50$} & \multirow[t]{2}{*}{7,80} & $\mathrm{r}$ & $-0,060$ & 0,062 \\
\hline & & & $\mathrm{p}$ & 0,346 & 0,326 \\
\hline \multirow{2}{*}{ Kreatine } & \multirow[t]{2}{*}{$, 42-8,03$} & \multirow[t]{2}{*}{1,22} & $\mathrm{r}$ & 0,092 & $-0,002$ \\
\hline & & & $\mathrm{p}$ & 0,147 & 0,976 \\
\hline \multirow{2}{*}{ Miyoglobin } & \multirow[t]{2}{*}{$2,30-50000,00$} & \multirow[t]{2}{*}{99,90} & $\mathrm{r}$ & 0,010 & 0,055 \\
\hline & & & $\mathrm{p}$ & 0,870 & 0,384 \\
\hline \multirow{2}{*}{$\mathbf{E F}$} & \multirow[t]{2}{*}{$10,00-65,00$} & \multirow[t]{2}{*}{40,0} & $\mathrm{r}$ & 0,027 & $-0,102$ \\
\hline & & & $\mathrm{p}$ & 0,674 & 0,107 \\
\hline \multirow{2}{*}{$\mathrm{Hg}$} & \multirow[t]{2}{*}{$6,00-35,00$} & \multirow[t]{2}{*}{11,50} & $\mathrm{r}$ & $-0,074$ & 0,053 \\
\hline & & & $\mathrm{p}$ & 0,242 & 0,408 \\
\hline
\end{tabular}

BBÖ: Bakım bağımlılı̆̆ ölçeği, AKYÖBÖ: Avrupa Kalp Yetersizliği Öz Bakım Davranışı Ölçeği, TC: Trigliserit, BUN: Blood urea nitrogen, EF: Ejeksiyon fraksiyonu, Hg: Hemoglobin. 
Tablo 5. Bireylerin BBÖ ve AKYÖBÖ ortalamalarının bağımsızlık durumunu etkileyebilen bazı faktörler ile karşılaştırılması $(\mathrm{N}=392)$.

\begin{tabular}{|c|c|c|c|c|c|c|}
\hline \multicolumn{2}{|c|}{ Değişkenler } & \multicolumn{2}{|c|}{ BBÖ $(\chi \pm s d)$} & & \multirow{2}{*}{\multicolumn{2}{|c|}{$\begin{array}{c}\text { AKYÖBD }\left(\chi^{ \pm s d}\right) \\
33,33 \pm 8,88\end{array}$}} \\
\hline \multirow[t]{3}{*}{ Yaş } & 65 ve alt1 & $84(33,6)$ & $56,80 \pm 20,16$ & & & \\
\hline & 66 ve üstü & $166(66,4)$ & $53,83 \pm 19,27$ & & \multicolumn{2}{|c|}{$33,04 \pm 9,69$} \\
\hline & MU;p & & $6313,000 *$ & 0,222 & $6805,500^{*}$ & 0,759 \\
\hline \multirow{3}{*}{$\begin{array}{c}\text { Birlikte Yaşa- } \\
\text { nılan kişi }\end{array}$} & Yalnız & $161(7,6)$ & $62,84 \pm 19,56$ & & \multicolumn{2}{|c|}{$36,15 \pm 8,99$} \\
\hline & Ailem & $231(92,4)$ & $54,17 \pm 19,48$ & & \multicolumn{2}{|c|}{$32,89 \pm 9,42$} \\
\hline & MU;p & & $1652,500 *$ & $<0,05$ & $1644,500 *$ & $<0,05$ \\
\hline \multirow{3}{*}{$\begin{array}{l}\text { Başka Kronik } \\
\text { Hastalık Du- } \\
\text { rumu }\end{array}$} & Evet & $160(64,0)$ & $55,35 \pm 20,17$ & & \multicolumn{2}{|c|}{$33,20 \pm 9,52$} \\
\hline & Hayır & $90(36,0)$ & $53,91 \pm 18,58$ & & \multicolumn{2}{|c|}{$33,04 \pm 9,25$} \\
\hline & MU;p & & $6877,500 *$ & 0,557 & $7135,500^{*}$ & 0,906 \\
\hline \multirow{3}{*}{$\begin{array}{l}\text { Kalp Hastalığ1 } \\
\text { Dışında Dü- } \\
\text { zenli Kullanı- } \\
\text { lan İlaçlar }\end{array}$} & Evet & $193(77,2)$ & $54,04 \pm 19,67$ & & \multicolumn{2}{|c|}{$32,97 \pm 9,08$} \\
\hline & Hayır & $57(22,8)$ & $57,52 \pm 19,23$ & & \multicolumn{2}{|c|}{$33,70 \pm 10,50$} \\
\hline & MU;p & & $4916,500 *$ & 0,223 & $5290,500 *$ & 0,661 \\
\hline \multirow{5}{*}{$\begin{array}{l}\text { NHYA Sinıf- } \\
\text { laması }\end{array}$} & 1 & $4(1,6)$ & $54,00 \pm 28,40$ & & \multicolumn{2}{|c|}{$31,50 \pm 13,77$} \\
\hline & 2 & $99(39,6)$ & $58,23 \pm 19,44$ & & \multicolumn{2}{|c|}{$33,23 \pm 9,86$} \\
\hline & 3 & $116(46,4)$ & $54,08 \pm 18,46$ & & \multicolumn{2}{|c|}{$33,33 \pm 9,54$} \\
\hline & 4 & $31(12,4)$ & $46,90 \pm 21,38$ & & \multicolumn{2}{|c|}{$32,35 \pm 6,92$} \\
\hline & KW;p & & $8,504 * *$ & $<0,05$ & $0,671 * *$ & 0,880 \\
\hline \multirow[t]{3}{*}{ Cinsiyet } & Kadın & $136(54,4)$ & $53,52 \pm 18,88$ & & \multicolumn{2}{|c|}{$33,52 \pm 9,10$} \\
\hline & Erkek & $114(45,6)$ & $56,39 \pm 20,37$ & & \multicolumn{2}{|c|}{$32,69 \pm 9,78$} \\
\hline & MU;p & & $7134,500 *$ & 0,278 & $7305,000 *$ & 0,432 \\
\hline \multirow[t]{5}{*}{ BKI } & Zayıf $<18,5$ & $9(3,6)$ & $51,66 \pm 19,97$ & & \multicolumn{2}{|c|}{$32,33 \pm 6,51$} \\
\hline & $\begin{array}{c}\text { Normal } 18,5- \\
24,9 \\
\end{array}$ & $68(27,2)$ & $55,14 \pm 19,68$ & & \multicolumn{2}{|c|}{$33,82 \pm 9,62$} \\
\hline & $\begin{array}{c}\text { Fazla Kilolu } \\
25,0-29,9\end{array}$ & $103(42,2)$ & $54,07 \pm 19,49$ & & \multicolumn{2}{|c|}{$31,94 \pm 9,23$} \\
\hline & Obez $>30,0$ & $70(28,0)$ & $56,05 \pm 19,92$ & & \multicolumn{2}{|c|}{$34,35 \pm 9,71$} \\
\hline & KW;p & & $0,822 * *$ & 0,844 & $2,902 * *$ & 0,407 \\
\hline
\end{tabular}

*MU: Mann Whitney U testi, **KW: Kruskall Wallis testi, $\mathrm{p}$ : $\mathrm{p}<0,05$ anlamlılık olarak alındı ve koyu punto ile belirtildi, BKI: Beden kitle indeksi. 